\title{
Normal median nerve proximal latency in carpal tunnel syndrome: a clue to coexisting Martin-Gruber anastomosis ${ }^{1}$
}

\author{
V. IYER AND G. M. FENICHEL 2 \\ From the Department of Neurology and The Jerry Lewis Neuromuscular Disease Research Center, \\ Vanderbilt University School of Medicine, USA
}

SYNOPSIS Five of 65 patients referred for electrodiagnosis because of clinical evidence of carpal tunnel syndrome were found to have near normal latency on proximal stimulation of the median nerve, although the distal motor latency was prolonged. In one patient, the proximal latency was actually shorter than the distal latency. The failure of the proximal latency to be prolonged in proportion to the distal latency results in a spuriously high apparent conduction velocity in the forearm segment of the nerve. This value may even exceed the conduction velocity of the corresponding nerve segment in the unaffected arm. Stimulation studies on the ulnar nerve reveal that this disparity is the result of some of the median nerve fibres destined for the thenar muscles taking an aberrant course through the ulnar nerve and thus escaping compression at the wrist. A median-ulnar communication in the forearm, the 'Martin-Gruber' anastomosis, may occur in up to $15 \%$ of the population. The presence of the Martin-Gruber anastomosis in patients with carpal tunnel syndrome results in a partial or total sparing of thenar muscles from denervation and the paradoxical recording of normal proximal latencies in the median nerve when the distal latency is prolonged.

A communication between the median and ulnar nerves in the forearm, often known by the eponym Martin-Gruber anastomosis, occurs in about $15 \%$ of the normal population (Mannerfelt, 1966). This anomaly is asymptomatic and often goes undetected. However, with injuries or other disturbances of the ulnar or median nerves, the presence of the anomaly is revealed by the unusual distribution of the motor and/or sensory deficit. It is conceivable that such an anomaly could alter the electroneurographic findings in cases of carpal tunnel syndrome. The authors have examined five such individuals in whom the most striking finding was a near normal median nerve proximal latency in the

\footnotetext{
${ }^{1}$ Supported in part from a grant from Muscular Dystrophy Association, Inc. Presented at the 5th International Congress of Electromyography held at Rochester, Minnesota, September 1975.

${ }^{2}$ Address for reprint requests: Dr G. M. Fenichel, Department of Neurology, Vanderbilt University School of Medicine, Nashville, Tennessee 37232, USA.

(Accepted 30 December 1975.)
}

presence of prolonged distal latency, resulting in a spuriously high calculated conduction velocity proximal to the wrist. To the best of our knowledge the only previous reference to this finding is by Buchthal et al., (1974). The paucity of available literature on this phenomenon prompted this report.

All the patients were investigated in the electromyography laboratory of Vanderbilt University Hospital. Sixty-five cases of carpal tunnel syndrome were evaluated during the period July 1974 to April 1975 . We first became aware of a modification of the electrodiagnostic findings in carpal tunnel syndrome by coexisting median-ulnar anastomosis when we saw a patient in whom the proximal latency of the median nerve was apparently shorter than the distal latency. A prospective study of all patients with carpal tunnel syndrome seen later uncovered four more cases, though with less striking findings. The first patient is described in detail 
and the findings in the others given in tabular form.

\section{CASE REPORT}

CASE 1 A 69 year old female had had symptoms suggestive of carpal tunnel syndrome for the past two years. Loss of sensation in the median nerve distribution with moderate atrophy of the thenar muscles was noted bilaterally. Electromyographic examination was done using a TECA-4 machine. Silver disc electrodes of $5 \mathrm{~mm}$ diameter were placed over the abductor pollicis brevis muscle and connected to the preamplifier. An earth (ground) electrode was placed over the dorsum of the hand. The right median nerve was stimulated with supramaximal stimuli at the wrist and elbow. Stimulation at the wrist evoked a muscle action potential of $0.5 \mathrm{mV}$, with a latency of $16.6 \mathrm{~ms}$ (distal latency). On stimulation at the elbow, the latency of the muscle action potential was found to be $9.4 \mathrm{~ms}$ (proximal latency) with an amplitude of $2 \mathrm{mV}$. Since the findings were unusual, the study was repeated with careful positioning of the stimulating electrode to avoid inadvertent simultaneous stimulation of the ulnar nerve. The findings were consistent even on recording with a needle electrode in the abductor pollicis brevis. Keeping the recording electrodes in the same position, the ulnar nerve was stimulated at the wrist and elbow. The potential recorded on distal stimulation was larger than that on proximal stimulation (Table 1). Stimulation of the ulnar nerve and recording from the abductor digiti minimi yielded normal values of latency and conduction velocity. Needle electromyography of the abductor pollicis brevis revealed the presence of fibrillations, polyphasic motor unit potentials of wide duration, and a reduced interference pattern. The opponens and flexor pollicis brevis muscles did not show any significant abnormality. Similar findings were noted on the left side as well. The patient was re-examined three months after corrective surgery on the right wrist. The distal latency was reduced to $10.5 \mathrm{~ms}$ and the proximal latency remained at $9.4 \mathrm{~ms}$.

Four subsequent patients referred for electroneurographic confirmation of diagnosis of carpal tunnel syndrome showed a characteristic lack of prolongation of the median nerve proximal latency in proportion to distal latency. The results of their studies are summarized in Table 2.

\section{DISCUSSION}

Anatomical variations in the innervation of intrinsic hand muscles are well known. A recent electromyographic study by Rosen (1973) has shown that anomalous distribution of the median and ulnar nerves may occur in as much as $20 \%$ of a normal population. The variations may consist of supplementary or dual innervation or complete replacement of one nerve territory by the other, as in the 'all ulnar' or the 'all median' hands' (Marinacci, 1964). These anomalies in innervation are often the result of communicationse between the ulnar and the median nerves in the forearm or the hand. The latter is less common and results in overlap of sensory supply. Com munications in the forearm are most common in the upper part (Sunderland, 1968), usually travelling from the median to the ulnar nerve, leading to an extension of ulnar nerve territory to include the usually median innervated thenar muscles partially or completely. These anastomotic fibres will escape compression in a case of

TABLE 1

ELECTRONEUROGRAPHIC FINDINGS IN CASE 1

\begin{tabular}{|c|c|c|c|c|}
\hline Nerve & $\begin{array}{l}\text { Stimulating } \\
\text { electrode }\end{array}$ & $\begin{array}{l}\text { Recording } \\
\text { electrode }\end{array}$ & $\begin{array}{l}\text { Latency } \\
\quad(m s)\end{array}$ & $\begin{array}{c}\text { Amplitude } \\
(m V)\end{array}$ \\
\hline $\begin{array}{l}\text { R. median } \\
\text { R. ulnar } \\
\text { L. median } \\
\text { L. ulnar } \\
\text { R. ulnar } \\
\text { L. ulnar }\end{array}$ & $\begin{array}{l}\text { Wrist } \\
\text { Elbow } \\
\text { Wrist } \\
\text { Elbow } \\
\text { Wrist } \\
\text { Elbow } \\
\text { Wrist } \\
\text { Elbow } \\
\text { Wrist } \\
\text { Elbow } \\
\text { Wrist } \\
\text { Elbow }\end{array}$ & $\begin{array}{l}\text { APB } \\
\text { APB } \\
\text { APB } \\
\text { APB } \\
\text { APB } \\
\text { APB } \\
\text { APB } \\
\text { APB } \\
\text { ADM } \\
\text { ADM } \\
\text { ADM } \\
\text { ADM }\end{array}$ & $\begin{array}{r}16.6 \\
9.4 \\
4.3 \\
8.9 \\
14.5 \\
9.5 \\
4.5 \\
9.0 \\
2.9 \\
6.6 \\
2.8 \\
7.8\end{array}$ & $\begin{array}{l}0.5 \\
2.0 \\
3.5 \\
2.0 \\
0.5 \\
3.0 \\
3.0 \\
2.0 \\
6.0 \\
6.0 \\
5.0 \\
5.0\end{array}$ \\
\hline
\end{tabular}


TABLE 2

SUMMARY OF MEDIAN NERVE CONDUCTION STUDIES IN THE FIVE CASES

\begin{tabular}{|c|c|c|c|c|c|c|c|}
\hline No. & $\begin{array}{c}\text { Patient } \\
\text { Age } \\
(y r)\end{array}$ & Sex & Side & $\begin{array}{c}\text { Distal latency } \\
\quad(m s)\end{array}$ & $\begin{array}{c}\text { Proximal latency } \\
(m s)\end{array}$ & $\begin{array}{l}\text { Conduction velocity } \\
\qquad(\mathrm{m} / \mathrm{s})\end{array}$ & Comment \\
\hline 1 & 69 & $\mathbf{F}$ & $\begin{array}{l}\text { Right } \\
\text { Left }\end{array}$ & $\begin{array}{l}16.6 \\
14.5\end{array}$ & $\begin{array}{l}9.4 \\
9.5\end{array}$ & - & $\begin{array}{l}\text { Proximal latency } \\
\text { Distal latency }\end{array}$ \\
\hline 2 & 65 & $\mathbf{F}$ & $\begin{array}{l}\text { Right } \\
\text { Left }\end{array}$ & $\begin{array}{l}8.0 \\
4.6\end{array}$ & $\begin{array}{r}10.6 \\
9.0\end{array}$ & $\left.\begin{array}{r}103.8 \\
59.1\end{array}\right]$ & \\
\hline 3 & 53 & $\mathbf{F}$ & $\begin{array}{l}\text { Right } \\
\text { Left }\end{array}$ & $\begin{array}{l}4.5 \\
7.0\end{array}$ & $\begin{array}{r}9.2 \\
10.4\end{array}$ & $\begin{array}{l}61.7 \\
82.0\end{array}$ & Conduction velocity faster on \\
\hline 4 & 41 & $\mathbf{M}$ & $\begin{array}{l}\text { Right } \\
\text { Left }\end{array}$ & $\begin{array}{l}4.5 \\
8.2\end{array}$ & $\begin{array}{r}9.3 \\
11.0\end{array}$ & $\begin{array}{l}71.0 \\
92.8\end{array}$ & the more affected side \\
\hline 5 & 34 & $\mathbf{M}$ & $\begin{array}{l}\text { Right } \\
\text { Left }\end{array}$ & $\begin{array}{c}\text { No MAP } \\
10.0\end{array}$ & $\begin{array}{c}\text { No MAP } \\
12.7\end{array}$ & $\overline{8.8}$ & \\
\hline
\end{tabular}

MAP: evoked muscle action potential.

carpal tunnel syndrome as they bypass the tunnel along with the fibres of the ulnar nerve (Figure).

The median-ulnar communications in the forearm were first described by the Swedish anatomist Martin, in 1763, and later by Gruber who demonstrated its presence in $15.2 \%$ of the arms dissected by him (quoted by Mannerfelt, 1966). Mannerfelt (1966) made a thorough study of these communications by electric stimulation and selective nerve blockade and demonstrated six examples among 41 subjects. The high incidence of similar communications in monkeys and other animals indicates that the anastomosis is of phylogenetic significance, reminiscent of the common ventral nerve trunk innervating flexor muscles of the upper extremity which is noted in the early stages of evolution.

The presence of such an anastomosis will lead to partial or total sparing of thenar muscles from the effects of compression of their nerve supply in a case of carpal tunnel syndrome. In cases of partial sparing the distal latency of the median nerve will be prolonged, but on stimulation at the elbow the latency will be normal as the stimulus can travel along the non-compressed fibres constituting the anastomosis and escaping the retinaculum via the ulnar nerve (Figure). This is the cause of the near normal proximal latency resulting in the apparent short conduction time in the forearm segment of the median nerve and the spuriously high calculated conduction velocity. The potential will be small on distal median nerve stimulation and large on proximal stimulation. The opposite is found on ulnar nerve stimulation. Thus, the presence of a prolonged distal latency, a near normal proximal

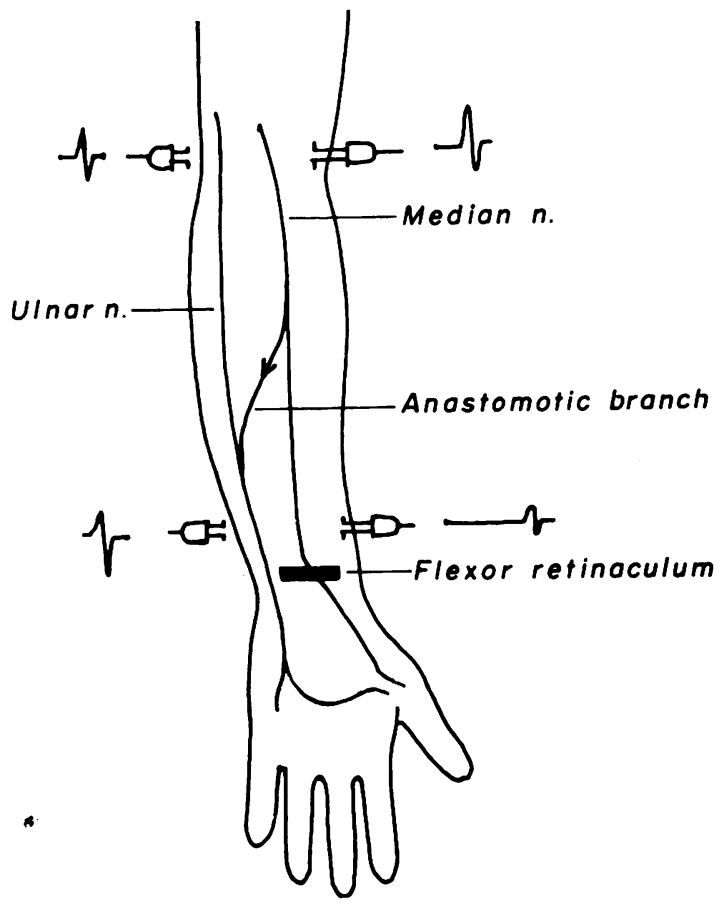

FIGURE Modifications of findings of carpal tunnel syndrome by coexisting Martin-Gruber anastomosis: median nerve proximal latency is not prolonged in proportion to distal latency and the evoked muscle action potential is much larger on proximal compared with distal stimulation.

median nerve latency, and spuriously high calculated conduction velocity in the forearm in a case of carpal tunnel syndrome should arouse suspicion of a coexisting Martin-Gruber anastomosis. The chances of detecting the anomaly are 
greater in advanced cases, since the numerical difference between the distal and proximal latency values becomes less. The difference in the amplitude of the potential between proximal and distal median stimulation, with converse findings on ulnar stimulation, is also diagnostic.

\section{REFERENCES}

Buchthal, F., Rosenfalck, A., and Trojaborg, W. (1974.) Electrophysiological findings in entrapment of median nerve at wrist and elbow. Journal of Neurology, Neurosurgery, and Psychiatry, 37, 340-360.
Mannerfelt, L. (1966). Studies on the hand in ulnar nerve paralysis. A clinical experimental investigation in normal and anomalous innervation. Acta Orthopedica Scandinavica, suppl. 87, pp. 23-142.

Marinacci, A. A. (1964). Diagnosis of 'all median hand' Bulletin of the Los Angeles Neurological Society, 29, 191-197.

Rosen, A. D. (1973). Innervation of the hand: an electromyographic study. Electromyography and Clinical Neurophysiology, 13, 175-178.

Sunderland, S. (1968). The median nerve: anatomical features. In Nerve and Nerve Injuries, pp. 747-757. Williams and Wilkins: Baltimore. 